\title{
Wound healing effects of Persian walnut (Juglans regia L.) green husk on the incision wound model in rats
}

\author{
Ayat Taheri (1), Sayid Mahdi Mirghazanfari (2), Masoumeh Dadpay (3) \\ (1) AJA University of Medical Sciences, Tehran, Iran; (2) Department of Physiology and Iranian \\ Medicine, School of Medicine, AJA University of Medical Sciences, Tehran, Iran; (3) \\ Department of Pathology, AJA University of Medical Sciences, Tehran, Iran \\ This article is distributed under the terms of the Creative Commons Attribution Noncommercial License (CC BY-NC 4.0) which permits \\ any noncommercial use, distribution, and reproduction in any medium, provided the original author(s) and source are credited.
}

\begin{abstract}
Walnut green husk (WGH) has been mentioned as a wound-healing agent in traditional Iranian medicine. Although previous studies indicated that WGH is a good source of pharmaceutical ingredients, they did not assess its wound healing activity; so the present study set out the scientific validation of the wound healing potential of the Persian walnut. Total phenolic content, reducing power, DPPH, and nitric oxide scavenging activity of aqueous ethanol extract of WGH was evaluated. Forty-eight male Wistar albino rats were divided into four groups of 12 each. An incision wound was created on the dorsal region of each rat. WGH extract $(20 \% \mathrm{w} / \mathrm{w})$, WGH burnt residues $(20 \% \mathrm{w} / \mathrm{w})$, Eucerin, and Phenytoin ointments were used in each group. Wound length, contraction percentage, and histopathological evaluations were recorded on days 3, 7, 10, and 14. Total phenolic content and $\mathrm{EC}_{50}$ values of reducing power, $\mathrm{DPPH}$ and nitric oxide scavenging activity of the WGH extract were $61.34 \pm 0.64 \mathrm{mg} / \mathrm{g}$ dry extract, $0.95 \pm 0.02 \mathrm{mg} / \mathrm{mL}$, $0.35 \pm 0.01 \mathrm{mg} / \mathrm{mL}$, and $0.28 \pm 0.01 \mathrm{mg} / \mathrm{mL}$, respectively. Treated animals with WGH extract showed significantly $(\mathrm{p} \leq 0.05)$ better results for physical and pathological parameters compared to the control group; overall, WGH extract showed better results than WGH burnt residues. The present study indicated that the WGH aqueous ethanol extract has a promising potential for wound healing in the animal model and could be a valuable resource for developing new woundhealing medicines for humans.
\end{abstract}

Key Words: antioxidant, Juglans regia, Persian walnut, traditional Iranian (Persian) medicine, wound healing.

Eur J Transl Myol 30 (1): 210-2018, 2020

Wound refers to a laceration or breakdown of the skin tissues or membranes as a result of damage caused by physico-chemical and biological factors. The wound healing process includes coagulation, inflammation, proliferation, and remodeling phases. ${ }^{1}$ Chronic wounds and delayed wound healing are among the most challenging problems in today's medicine, and impose many socio-economic issues on patients. ${ }^{2}$ Recent developments in medical sciences have heightened the need for developing the healing agents to speed up the wound healing process. Therefore, the use of herbal remedies, along with conventional methods, has attracted attention in recent years. The use of complementary and alternative medicine (CAM) and medicinal plants in the treatment of various types of wounds, such as incisions, burns, etc., has a long history in many countries. In traditional Iranian (Persian) medicine (TIM/PM), there are many different ways of using medicinal plants for the treatment of diseases, which are linked to the vast geographical area and high plant diversity of Iran; as many as 1200 species of medicinal plants have been reported for the flora of Iran. ${ }^{3}$ Plants have a wide variety of pharmaceutical ingredients with different biological activities, including anti-inflammatory, antimicrobial, and antioxidant; such properties have a crucial role in the wound healing process. ${ }^{4}$ The Persian walnut (Juglans regia $\mathrm{L}$.) is a monoecious tree with imperfect flowers and belongs to the Juglandaceae family. Different parts of the Persian walnut have been used to treat a range of diseases, including skin disorders, cancer, infectious disease, diarrhea, hyperglycemia, anorexia, arthritis helminthiasis, sinusitis, eczema, asthma. ${ }^{5}$ Although different drug forms of the walnut green husk (WGH), the extract and burnt residues, were referred to as the wound-healing agents in the TIM/PM resources and previous reports indicated that the plant is a good source of phenolic compounds with high antioxidant potential. ${ }^{5,6}$ 


\section{Effects of Persian walnut green husk on rat wound healing}

Eur J Transl Myol 30 (1): 210-218, 2020

Scientific research on effects on wound healing is lacking. WGH extract and burnt residues are evaluated on incision wound healing in rats.

\section{Materials and Methods}

\section{Collection and identification of plant materials}

Ripe walnut fruits were collected from the Saman region (32 28'59.4"N 50 54'52.4"E) in Chaharmahal and Bakhtiari province, Iran. Identification of samples was performed by academic staff in the department of horticultural science and landscape engineering, university of Tehran, Karaj, Iran, and the voucher specimen (No. 2019-1245) was preserved in the herbarium of the University of Tehran.

\section{Preparation of extract and burnt residue}

Previous studies reported that binary-solvent systems are more desirable for the extraction of phenolic compounds from plant samples than mono-solvent systems, ${ }^{7}$ so in the present study, we used $75 \%$ aqueous ethanol (ethanol: water, 75:25 v/v). At first, WGHs were washed under running tap water and were air-dried under shade. Then the samples were finely powdered using a mixer grinder before further studies. The powdered samples $(200 \mathrm{~g})$ were mixed with $2.0 \mathrm{~L}$ of aqueous ethanol and incubated for 72 hours in a shaker incubator at $37^{\circ} \mathrm{C}$ and $80 \mathrm{rpm}$. Whatman No. 1 filter paper was used for the filtration procedure. Afterward, solvents were evaporated at 40-45 ${ }^{\circ} \mathrm{C}$ using a vacuum evaporator (Heidolph-Laborota 4001), and then plant extracts were stored in the dark at $4{ }^{\circ} \mathrm{C}$ until being used in the experiment. The yield of the extract was about $20 \%$ of the crude powder. For the preparation of burnt residues, the powdered samples were placed in a laboratory electric furnace (WiseTherm) at $650{ }^{\circ} \mathrm{C}$ for 5 hours. Burnt residues collected after cooling have been preserved in the appropriate containers before use.

\section{Quantification assays}

Measurement of total phenolic contents

The amount of total phenolic content in the extract was determined using the Folin-Ciocalteu method. ${ }^{8}$ Briefly, $40 \mu \mathrm{L}$ of sample extract dissolved in EtOH $(2 \mathrm{mg} / \mathrm{mL})$ was mixed with $200 \mu \mathrm{L}$ of Folin-Ciocalteu reagent $(2.0$ $\mathrm{N})$ and $1160 \mu \mathrm{L}$ of distilled water. After $5 \mathrm{~min}$ in dark condition, $600 \mu \mathrm{L}$ of sodium carbonate $(20 \% \mathrm{v} / \mathrm{w})$ was added, and the mixture was incubated at $40^{\circ} \mathrm{C}$ for $30 \mathrm{~min}$. The mixture was subsequently centrifuged at $2000 \times \mathrm{g}$ for $10 \mathrm{~min}$, and the absorbance of the supernatant was measured at $765 \mathrm{~nm}$ using a spectrophotometer. The Gallic acid (GA) calibration curve was generated using the standard GA solutions $(50-500 \mu \mathrm{g} / \mathrm{mL})$ and the amount of total phenolic contents was calculated based on the equation $y=0.0078 x+0.2487, R^{2}=0.9885$ where $\mathrm{y}$ was the absorbance and $\mathrm{x}$ was the Gallic acid equivalent. The results were expressed as $\mathrm{mg}$ Gallic acid equivalents per gram of extract (GAE/g extract).
In vitro antioxidant assays: Determination of reducing power

Determination of the reducing power of the extracts was done according to the previously described procedure. ${ }^{9}$ Different concentrations $(0.01-5 \mathrm{mg} / \mathrm{mL})$ of the extract $(1 \mathrm{~mL})$ was mixed with $2.5 \mathrm{~mL}$ of sodium phosphate buffer $(200 \mathrm{mmol} / \mathrm{L})(\mathrm{pH}=6.6)$ and $2.5 \mathrm{~mL}$ of potassium ferricyanide solution $(1 \% \mathrm{w} / \mathrm{v})$. The mixture was incubated at $50{ }^{\circ} \mathrm{C}$ for 20 minutes. After that, $2.5 \mathrm{~mL}$ of trichloroacetic acid $(10 \% \mathrm{w} / \mathrm{v})$ was added, and then the resulting mixture was centrifuged at $1000 \mathrm{rpm}$ for 8 minutes. The supernatant $(2.5 \mathrm{~mL})$ was mixed with 2.5 $\mathrm{mL}$ of distilled water and $0.5 \mathrm{~mL}$ of ferric chloride solution $(0.1 \%)$. The absorbance was measured at 700 $\mathrm{nm}$. The extract concentration providing 0.5 of absorbance $\left(E_{50}\right)$ was calculated from the graph of absorbance at $700 \mathrm{~nm}$ against the correspondent extract concentration.

In vitro antioxidant assays: DPPH radical scavenging activity

The DPPH scavenging ability of the extracts was evaluated using the method of Hatano et al. (1988). ${ }^{10}$ Extract solutions $(0.3 \mathrm{~mL})$ with different concentrations (0.01-2 mg/mL) were mixed with $2.7 \mathrm{~mL}$ of fresh DPPH methanolic solution $\left(6 \times 10^{-5} \mathrm{M}\right)$. The resulting mixture was shaken vigorously and placed at room temperature and dark for $60 \mathrm{~min}$. The reduction of DPPH radicals was measured by monitoring the decrease in absorbance at $517 \mathrm{~nm}$. The DPPH scavenging activity was calculated using the following formula:

DPPH scavenging activity $(\%)=\left[\frac{\mathrm{A}_{\mathrm{x}}-\mathrm{A}_{\mathrm{o}}}{\mathrm{A}_{\mathrm{x}}}\right] \times 100$

where; $A_{x}$ was the absorbance of the control reaction without the test material, and $\mathrm{A}_{\mathrm{o}}$ was the absorbance of the test material. The $\mathrm{EC}_{50}$ was calculated from the graph of the scavenging effect percentage against the concentration of the extract in the solution

In vitro antioxidant assays: Nitric oxide scavenging activity

The nitric oxide (NO) scavenging activity of the samples was determined using the method of Sousa et al. (2008).

${ }^{11}$ Different concentrations $(100 \mu \mathrm{L})$ of the extracts were mixed with $100 \mu \mathrm{L}$ of sodium nitroprusside solution (SNP, $10 \mathrm{mM}$ ), and the mixture was kept for $60 \mathrm{~min}$ at room temperature and light condition. Each sample was reacted with $100 \mu \mathrm{L}$ of Griess reagent (1\% sulphanilamide, $\quad 0.1 \% \quad$ naphthylethylenediamine dichloride and $2 \%$ phosphoric acid). The resulting mixture was incubated at room temperature for $10 \mathrm{~min}$, and the absorbance was measured at $562 \mathrm{~nm}$. NO scavenging activity and $\mathrm{EC}_{50}$ were determined according to the process described for the DPPH method.

In vivo study of wound healing: Experimental animals In this experimental study, 48 male Wistar albino rats weighing 180 to $200 \mathrm{~g}$ were used. Animals were kept in 
Table 1. Experimental design for in vivo wound healing study

\begin{tabular}{ll}
\hline Group name & Ingredients \\
\hline Control & Eucerin \\
Standard & Phenytoin cream $(1 \%)$ \\
Extract & $20 \%(w / w)$ WGH extract ointment \\
Burnt residues & $20 \%(w / w)$ WGH burnt residues ointment \\
\hline
\end{tabular}

separate cages under standard laboratory conditions (ambient temperature $25 \pm 3{ }^{\circ} \mathrm{C}$ and $12 \mathrm{~h} \mathrm{light/dark}$ cycle). Animals were fed standard pellets and water ad libitum throughout the test period (14 days). Rats were randomly divided into four groups of 12 each. The details of the statistical design are shown in Table 1. The concentration of the drug $(20 \% \mathrm{w} / \mathrm{w})$ was selected based on a pilot study with doses like $5 \%, 10 \%, 15 \%$, and $20 \%$ on the incision wound model in male Wistar albino rats and the concentration of $20 \%(\mathrm{w} / \mathrm{w})$ showed better results in case of wound healing. The present study followed the guidelines of the World Medical Association for the care and use of laboratory animals

In vivo study of wound healing: Incision wound model Animals in each group were anesthetized by a mixture of ketamine 10\% (80 mg kg-1; Alfasan, Netherlands) and xylazine $2 \%$ (10 $\mathrm{mg} \mathrm{kg}^{-1}$; Alfasan, Netherlands), injected intraperitoneally. Then the dorsal region of rats was shaved, and a 2-cm full-thickness incision wound was made through the skin. The wounds were photographed and left open, and the day of the surgery was considered as day 0 . The drugs were topically applied once daily until the $14^{\text {th }}$ day

In vivo study of wound healing: Physical parameters The physical wound parameters were measured on days $3,7,10$, and 14 to evaluate the wound healing process. Wound length was measured using a digital caliper. For evaluating the rest of the parameters, the cross-sections of the wounds were photographed on days $3,7,10$, and 14 , and images were analyzed using ImageJ software. The formulas are as follow: ${ }^{12}$

wound length percentage $=\frac{\text { wound length on day } \mathrm{x}(\mathrm{mm})}{\text { wound length on day } 0(\mathrm{~mm})} \times 100$

wound healing ratio $(\%$ contraction $)=\left[1-\frac{\text { wound area on day } \mathrm{x}\left(\mathrm{mm}^{2}\right)}{\text { wound area on day } 0\left(\mathrm{~mm}^{2}\right)}\right] \times 100$
In vivo study of wound healing: Histopathological study Three animals of each group were sacrificed on days 3, 7, 10, and 14 and wound tissues were collected and maintained in a $10 \%$ formalin solution and then embedded in paraffin wax. A $3 \mu \mathrm{m}$ thick cut was performed, and the samples were stained with hematoxylin and eosin (H\&E). ${ }^{13}$ The samples were observed under a light microscope, and the parameters, including re-epithelialization, polymorphonuclear cells (PMN), macrophage, neovascularization, and fibroblast, were blindly scored by a pathologist. Scores were as follow: 0 = no evidence, $1=$ minimal, $2=$ slight, $3=$ moderate and, $4=$ severe.

\section{Statistical analysis}

Statistical analysis was performed using SPSS, version

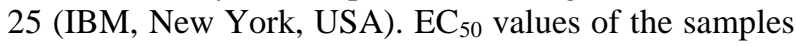
in the antioxidant assays were determined using GraphPad Prism 8.2.1. The data are represented as the mean \pm SEM, and the values were subjected to analysis of variance (ANOVA) with Tukey post-hoc tests. A probability level of $\mathrm{p} \leq 0.05$ was considered significant.

\section{Results}

\section{Total phenolic content and antioxidant activity}

Table 2 presents results of the total phenolic content, reducing power, DPPH, and nitric oxide scavenging activity.

In vivo study of wound healing: Physical parameters In order to investigate the effects of different treatments on wound healing, the wounds were photographed during the healing period (days $0,3,7,10,14$ ) (Figure 1) and the percentage of wound length and wound healing ratio (contraction percentage) of different animals of four treatment groups were measured (Table 3).

Table 2. Total phenolic content, reducing power, DPPH radical, and nitric oxide scavenging activities of $75 \%$ aqueous ethanol extract of WGH

\begin{tabular}{|c|c|c|c|c|}
\hline Medical part & $\begin{array}{lr}\text { Total } & \text { phenolic } \\
\text { content } \\
\text { extract } \\
\text { equivalent) }\end{array}$ & $\begin{array}{l}\text { Reducing power } \\
\left(\text { EC }_{50}\right) \mathrm{mg} / \mathrm{mL}\end{array}$ & $\begin{array}{l}\text { DPPH } \\
\mathrm{mg} / \mathrm{mL}\end{array}$ & $\begin{array}{l}\text { Nitric oxide } \\
\text { scavenging } \\
\text { activity (EC50) } \\
\text { mg/mL }\end{array}$ \\
\hline $\begin{array}{l}\text { Walnut green } \\
\text { husk (WGH) }\end{array}$ & $61.34 \pm 0.64$ & $0.95 \pm 0.02$ & $0.35 \pm 0.01$ & $0.28 \pm 0.01$ \\
\hline
\end{tabular}

Each value was obtained by calculating average of three experiments. Data are presented as Mean \pm SEM. 
Table 3. Physical evaluations of $20 \%(w / w)$ WGH ointment compared to the control and standard in the incision wound model in rats

\begin{tabular}{|c|c|c|}
\hline \multirow[b]{2}{*}{ Groups } & \multicolumn{2}{|c|}{ Wound Physical Parameters } \\
\hline & Wound length (\%) & $\begin{array}{c}\text { Wound healing ratio } \\
\text { (\% contraction) }\end{array}$ \\
\hline \multicolumn{3}{|l|}{ 3-Day application } \\
\hline Eucerin & $93.26 \pm 1.19^{\mathrm{a}}$ & $4.30 \pm 1.80^{b}$ \\
\hline Phenytoin & $90.84 \pm 0.67^{\mathrm{a}}$ & $7.51 \pm 0.69^{\mathrm{ab}}$ \\
\hline Extract & $81.41 \pm 2.65^{b}$ & $17.01 \pm 2.70^{\mathrm{a}}$ \\
\hline Burnt residues & $85.58 \pm 1.12^{\mathrm{a}}$ & $12.81 \pm 1.15^{\mathrm{ab}}$ \\
\hline \multicolumn{3}{|l|}{ 7-Day application } \\
\hline Eucerin & $72.00 \pm 0.61^{\mathrm{a}}$ & $26.88 \pm 0.62^{\mathrm{c}}$ \\
\hline Phenytoin & $63.69 \pm 0.73^{\text {bc }}$ & $35.22 \pm 0.74^{\mathrm{ab}}$ \\
\hline Extract & $58.35 \pm 1.76^{c}$ & $40.82 \pm 1.79^{\mathrm{a}}$ \\
\hline Burnt residues & $68.02 \pm 1.00^{\mathrm{ab}}$ & $31.13 \pm 1.02^{b c}$ \\
\hline \multicolumn{3}{|l|}{ 10-Day application } \\
\hline Eucerin & $49.41 \pm 0.93^{\mathrm{a}}$ & $46.08 \pm 1.02^{b}$ \\
\hline Phenytoin & $0.00^{b}$ & $100.00^{\mathrm{a}}$ \\
\hline Extract & $0.00^{b}$ & $100.00^{\mathrm{a}}$ \\
\hline Burnt residues & $44.49 \pm 1.60^{\mathrm{a}}$ & $51.58 \pm 1.74^{b}$ \\
\hline \multicolumn{3}{|l|}{ 14-Day application } \\
\hline Eucerin & $15.44 \pm 1.32^{\mathrm{a}}$ & $83.65 \pm 1.40^{b}$ \\
\hline Phenytoin & $0.00^{b}$ & $100.00^{\mathrm{a}}$ \\
\hline Extract & $0.00^{b}$ & $100.00^{\mathrm{a}}$ \\
\hline Burnt residues & $0.00^{b}$ & $100.00^{\mathrm{a}}$ \\
\hline
\end{tabular}

Data are means \pm SEM. Means with different letters are significantly different $(p<0.05)$.

As depicted in Table 3, until day 7, the highest wound healing was observed in the extract group (40.82\%); however, on day 10, both extract and standard groups showed complete wound healing. In the case of burnt residues, complete wound healing was observed on day $14^{\text {th }}$, but there was no proof of complete wound healing in the control group until the end of the experiment.

In vivo study of wound healing: Pathological parameters Figure 2 displays the results obtained from the histopathological evaluation of studied tissues. On the $3^{\text {rd }}$ day, there was no significant difference in reepithelialization between groups; however, on day $7^{\text {th }}$, reepithelialization in the WGH treated samples either ethanol extract and WGH burnt residues were significantly higher than the control group. On the $10^{\text {th }}$ day, although WGH extract and burnt residue ointments had significant differences in re-epithelialization compared to the control group, burnt residue ointment showed significantly lower values than the standard. Both WGH extract and burnt residues ointments exhibited significant differences with the control group on the $14^{\text {th }}$ day. There is a significant difference in the number of PMNs between WGH extract and the control on the $10^{\text {th }}$ day. Despite that the PMNs were less when compared with the burnt residues treated samples, they were significantly higher compared to the controls. 


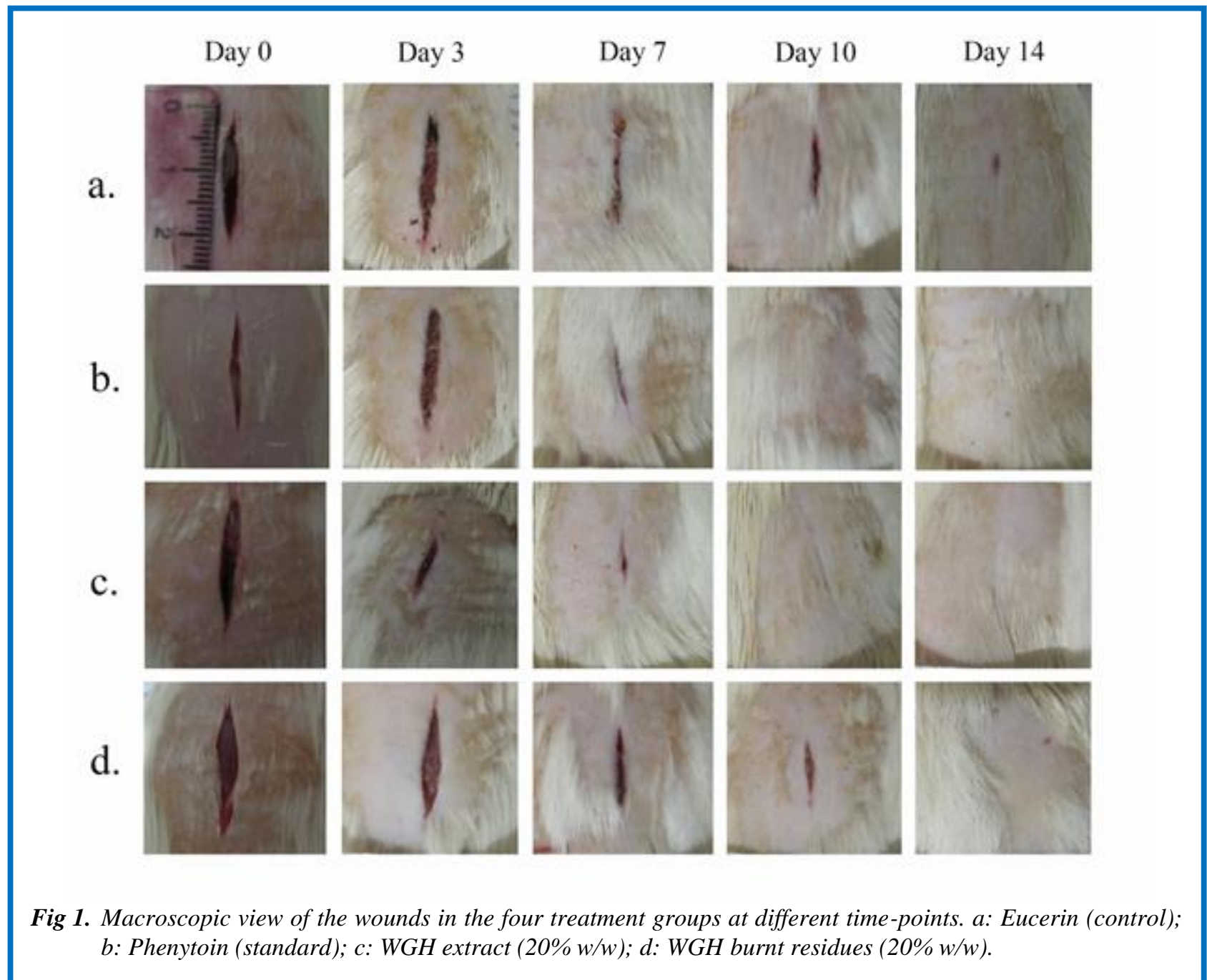

Although macrophage levels have increased in all treatments during the test period, their difference was never significant. On days $3^{\text {rd }}$ and $7^{\text {th }}$, neovascularization was increased in both WGH extract and burnt residue ointments samples, but the differences were not significant when compared to the control and standard groups. Although not significant, decreasing in neovascularization was observed, in WGH extract and burnt residues treatments on the $10^{\text {th }}$ and $14^{\text {th }}$ days. Also in fibroblasts, there were no significant differences between groups throughout the test period.

\section{Discussion}

The wound healing is a complicated process that involves the cooperation of different cell types toward restoration and re-epithelization of any discontinuity in the damaged skin. The wound healing has four stages: the first stage is the coagulation and homeostasis phase that occurs immediately after the creation of a wound in damaged skin. The second stage is the inflammatory phase, which protects the wound against the microorganisms. The third stage is the proliferation phase that involves proliferation and migration of keratinocytes, proliferation of fibroblasts, matrix deposition, and angiogenesis. Finally, the fourth stage is the remodeling phase, which involves scar tissue replacement, starting approximately on day $21^{\text {st }}$ and may take up to a year or more. ${ }^{14}$ Antioxidant compounds which are known for their free radical scavenging activity have a significant effect on the wound healing process. During the inflammation phase of wound healing, phagocytosis caused by monocytes, neutrophils, and, to a much less extent, by eosinophils leads to an oxidative burst in which there is a dramatic increase in oxygen consumption. The result of this increase is the accumulation of reactive oxygen and nitrogen derivatives. These derivatives have the ability to kill microorganisms directly, but they will also act as messengers and they are able to trigger signaling molecules; however, the damage in the affected area is inevitable by their large amount of production. ${ }^{15}$ It is, therefore, essential to determine the antioxidant effect of drugs and plants in order to provide information on their wound healing activities. ${ }^{16}$ The results of the present study indicated that the aqueous ethanol extract of WGH contains a high level of phenolic compounds $(61.34 \mathrm{mg} / \mathrm{g}$ dry extract (GAE equivalent)). The WGH contains 


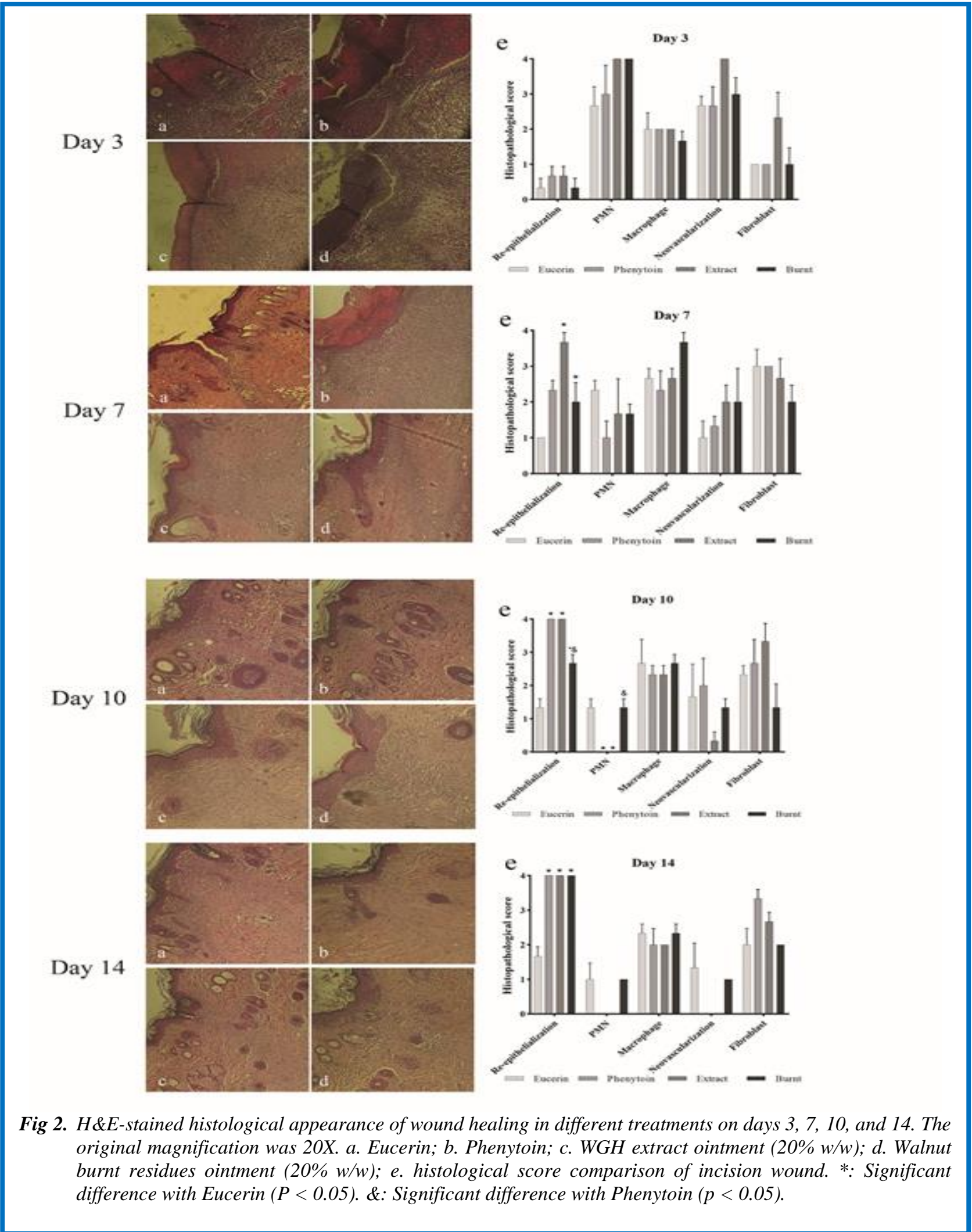

various phenolic compounds; among them, juglone (5hydroxy-1,4-naphthoquinone) is the characteristic of Juglans spp. ${ }^{17}$ Previous studies showed that total phenolic content could be different based on the variety, harvesting time, plant part, and the type of solvent used for the extraction process. ${ }^{6,18,19}$ The redox potential of medicinal plants is mainly due to their phenolic content, which qualifies them to serve as reducing compounds, 
donors of hydrogen, and scavengers of oxygen freeradicals. ${ }^{20}$ Previous studies have shown that there is a relationship between the phenolic content and the antioxidant ability of plant-origin compounds. ${ }^{21,22}$ In this study, three different assays were used to assess the antioxidant capacity of WGH samples against reactive oxygen species (ROS) species: reducing power, DPPH, and NO scavenging activity. The findings indicated that the extract of WGH is a rich source of antioxidants which have a vital role at the forefront of the battle against free radicals. In the present study, the extract of $\mathrm{WGH}$ showed a great reducing power $\left(\mathrm{EC}_{50}=0.95 \mathrm{mg} / \mathrm{mL}\right)$. The reducing power of a compound is an essential sign of its potential antioxidant activity. ${ }^{23}$ It can be inferred from higher values of reducing power, that some components serve as electron donors and interact with free radicals. DPPH assay is one of the most commonly used methods for evaluation of the free radical scavenging activity. The studied extract showed a high DPPH radical scavenging activity $\left(\mathrm{EC}_{50}=0.35 \mathrm{mg} / \mathrm{mL}\right)$. According to previous studies, DPPH activity in the WGH is concentrationdependent, and specimens with higher total phenols show higher DPPH activity. ${ }^{18,24}$ The WGH showed an $\mathrm{EC}_{50}$ of $0.28 \mathrm{mg} / \mathrm{mL}$ for the NO scavenging that was slightly lower compared to DPPH radical scavenging activity $\left(\mathrm{EC}_{50}=0.35 \mathrm{mg} / \mathrm{mL}\right)$. The $\mathrm{NO}$ has a significant role as a signaling molecule in various biological processes, including blood pressure regulation, defense mechanisms, immune regulation, and smooth muscle relaxation. When NO is overproduced, the system is unable to neutralize or eliminate the molecules of free radicals in excess and therefore, NO alters the protein structures and interferes with their normal function. ${ }^{25}$ From the above findings, we concluded that the extract of WGH has a high antioxidant power and could be used as a pharmacotherapeutic agent. The results from wound healing and wound repair length clearly showed that the groups treated with WGH ointment had similar results when compared with control groups. Nevertheless WGH burnt residues ointment had significantly better results than the control group, the standard did much better. Overall, the WGH extract ointment had better results than the WGH burnt residues ointment, probably due to the lack of organics like phenolic compounds in burnt residues. The presence of organics like phenolic compounds contribute to the higher antioxidant level. ${ }^{26}$ The presence of antioxidants in the extract will fasten the healing process. ${ }^{27}$ Probably, the improved wound healing results of the WGH extract are due to its antiinflammatory effects, along with its effect on the maturation and organization of the granulation tissue. ${ }^{28}$ For the histopathological evaluations, reepithelialization, PMN, macrophage, neovascularization, and fibroblast were studied. Re-epithelialization is known as an essential factor in the assessment of successful wound healing; this process is characterized by the migration of keratinocytes and increased proliferation across the wound area. In the case of chronic wounds, the process of epithelialization is disrupted, and the impaired wounds are the result of the lack of epithelialization. ${ }^{29}$ In this study, re-epithelialization in standard, WGH extract, and burnt residues ointment treatments were increased on days 7, 10, and 14 . Keratinocytes have several vital roles in the wound healing process including epidermis maintenance and restoration after wounding. ${ }^{29} \mathrm{PMNs}$ are also crucial for the wound healing; the fundamental role of PMNs is to release soluble mediators, including neutrophil elastase, matrix metalloproteinases (MMPs), and myeloperoxidase (MPO).$^{30} \mathrm{MPO}$ acts as a mediator for the killing of bacteria by the production of reactive oxygen species (ROS). In this study, from the $3^{\text {rd }}$ day to the end of the experiment, the PMNs decreased, and on the $10^{\text {th }}$ day, there were significant differences between WGH extract and control group. By its dynamic plasticity, macrophage plays a critical role in the inflammation phase of tissue repair, which allows macrophages to function both as a tissue-destructive and -reparative agents. ${ }^{31}$ In our study, the differences between treatments were not significant throughout the experiment. The formation of new blood vessels is essential for healthy wound healing.

The reduction of neovascularization on the $14^{\text {th }}$ day may suggest that WGH extract accelerates the process of wound healing. Fibroblasts are essential in all stages of wound healing; they play a vital role in the deposition of extracellular matrix (ECM) components, wound contraction and ECM remodeling. ${ }^{32}$ In the present study, fibroblasts have increased from day $3^{\text {rd }}$ to $14^{\text {th. }}$; although the differences were not statistically significant, standard and WGH extract groups exhibited higher values which may indicate the potential wound healing properties of WGH extract compared to the standard. In conclusion, the present study, for the first time, investigates the wound healing activity of the WGH.

In conclusion, the results of the wound healing ratio, along with histopathological evaluations, indicate that the ethanol extract of WGH has a promising wound healing capacity. These findings highlight the potential usefulness of plant-derived compounds for the treatment of wounds in both animals and humans.

\section{List of acronyms}

CAM - Complementary and alternative medicine DPPH - 2, 2-diphenyl-1-picrylhydrazyl

ECM - Extracellular matrix

GA - Gallic acid

GAE - Gallic acid equivalent

MMP - Matrix metalloproteinase

MPO - Myeloperoxidase

NO - Nitric oxide

PMN - Polymorphonuclear cells

ROS - Reactive oxygen species

SNP - Sodium nitroprusside

TIM/PM - Traditional Iranian (Persian) medicine WGH - Walnut green husk 


\section{Effects of Persian walnut green husk on rat wound healing}

Eur J Transl Myol 30 (1): 210-218, 2020

\section{Authors contributions}

All authors equally contributed to manuscript.

\section{Acknowledgments}

We would like to thank all those who have assisted in the collection of plant samples and laboratory procedures for this project

\section{Funding}

This work was supported by AJA University of Medical Sciences, Tehran, Iran, but this research received no other specific grant from any funding agency in the public, commercial or not for profit sectors.

\section{Conflict of Interest none}

\section{Ethical Publication Statement}

We confirm that we have read the Journal's position on issues involved in ethical publication and affirm that this report is consistent with those guidelines.

\section{Corresponding Author}

Sayid Mahdi Mirghazanfari; Department of Physiology and Iranian Medicine, School of Medicine, AJA University of Medical Sciences, Tehran, Iran; Phone: +989122765221; ORCID iD: 0000-0001-9295-4482

Email: smmirghazanfari@gmail.com

\section{E-mails of co-authors}

Ayat Taheri: taheri.aca@gmail.com ORCID iD: 0000-0003-1991-0779

Masoumeh Dadpay: mdadpay1@yahoo.com ORCID iD: 0000-0001-6384-4794

\section{References}

1. Gonzalez AC de O, Costa TF, Andrade $\mathrm{Z}$ de A, Medrado ARAP. Wound healing - A literature review. An Bras Dermatol 2016;91:614-20.

2. Nicolaus C, Junghanns S, Hartmann A, et al. In vitro studies to evaluate the wound healing properties of Calendula officinalis extracts. J Ethnopharmacol 2017;196:94-103.

3. Nordensram B. Rechinger, K. H. (ed.), Flora Iranica, Fasc. 111-162 (1975-1987). Nord J Bot 1989;8:625-6.

4. Barreto R, Albuquerque-Júnior R, Araújo A, et al. A Systematic Review of the Wound-Healing Effects of Monoterpenes and Iridoid Derivatives. Molecules 2014;19:846-62.

5. Panth N, Paudel KR, Karki R. Phytochemical profile and biological activity of Juglans regia. J Integr Med 2016;14:359-73.

6. Ghasemi K, Ghasemi Y, Ehteshamnia A, et al. Influence of environmental factors on antioxidant activity, phenol and flavonoids contents of walnut (Juglans regia L.) green husks. J Med Plants Res 2011;5:1128-33.

7. Chew KK, Khoo MZ, Ng SY, et al. Effect of ethanol concentration, extraction time and extraction temperature on the recovery of phenolic compounds and antioxidant capacity of Orthosiphon stamineus extracts. Int Food Res J 2011;18:1427.

8. AĞ ŞELECİ D, GÜMÜŞ ZP, YAVUZ M, et al. A case study on in vitro investigations of the potent biological activities of wheat germ and black cumin seed oil. Turkish J Chem 2015;39:801-12.

9. Berker KI, Güçlü K, Tor İ, Apak R. Comparative evaluation of $\mathrm{Fe}$ (III) reducing power-based antioxidant capacity assays in the presence of phenanthroline, batho-phenanthroline, tripyridyl triazine (FRAP), and ferricyanide reagents. Talanta 2007;72:1157-65.

10. Hatano T, Kagawa H, Yasuhara T, Okuda T. Two new flavonoids and other constituents in licorice root: their relative astringency and radical scavenging effects. Chem Pharm Bull 1988;36:2090-7.

11. Sousa A, Ferreira I, Barros L, et al. Antioxidant potential of traditional stoned table olives "Alcaparras": influence of the solvent and temperature extraction conditions. LWT-Food Sci Technol 2008;41:739-45.

12. Ozay Y, Kasim MC, Guzel-Ozay S, et al. Effects of Equisetum arvense Ointment on Diabetic Wound Healing in Rats. Wounds a Compend Clin Res Pract 2013;25:234-41.

13. Sirak A, Abie G. Manual of standard operating procedure (SOP) for tissue processing. Natl Anim Heal Investig Cent (NAHDIC), Ethiop 2009:8-32.

14. Velnar T, Bailey T, Smrkolj V. The wound healing process: an overview of the cellular and molecular mechanisms. J Int Med Res 2009;37:1528-42.

15. Tümen İ, Akkol EK, Taştan H, et al. Research on the antioxidant, wound healing, and antiinflammatory activities and the phytochemical composition of maritime pine ( Pinus pinaster Ait). J Ethnopharmacol 2018;211:235-46.

16. Shetty S, Udupa S, Udupa L. Evaluation of antioxidant and wound healing effects of alcoholic and aqueous extract of Ocimum sanctum Linn in rats. Evidence-Based Complement Altern Med 2008;5:95-101.

17. Mahoney N, Molyneux RJ, Campbell BC. Regulation of aflatoxin production by naphthoquinones of walnut (Juglans regia). J Agric Food Chem 2000;48:4418-21.

18. Fernández-Agulló A, Pereira E, Freire MS, et al. Influence of solvent on the antioxidant and antimicrobial properties of walnut (Juglans regia L.) green husk extracts. Ind Crops Prod 2013;42:12632.

19. Omidi Ghaleh Mohammadi M, Mirghazanfari SM. Investigation of Iranian pomegranate cultivars for wound healing components. Eur J Transl Myol 2019;29:22-6.

20. Hakkim FL, Shankar CG, Girija S. Chemical Composition and Antioxidant Property of Holy 


\section{Effects of Persian walnut green husk on rat wound healing}

Eur J Transl Myol 30 (1): 210-218, 2020

Basil (Ocimum sanctum L.) Leaves, Stems, and Inflorescence and Their in Vitro Callus Cultures. J Agric Food Chem 2007;55:9109-17.

21. Rice-Evans C. Flavonoid Antioxidants. Curr Med Chem 2001;8:797-807.

22. Fernández-Agulló A, Pereira E, Freire MS, et al. Influence of solvent on the antioxidant and antimicrobial properties of walnut (Juglans regia L.) green husk extracts. Ind Crops Prod 2013;42:12632.

23. Meir S, Kanner J, Akiri B, Philosoph-Hadas S. Determination and involvement of aqueous reducing compounds in oxidative defense systems of various senescing leaves. J Agric Food Chem 1995;43:1813-9.

24. Oliveira I, Sousa A, Ferreira ICFR, et al. Total phenols, antioxidant potential and antimicrobial activity of walnut (Juglans regia L.) green husks. Food Chem Toxicol 2008;46:2326-31.

25. Valko M, Leibfritz D, Moncol J, et al. Free radicals and antioxidants in normal physiological functions and human disease. Int $\mathbf{J}$ Biochem Cell Biol 2007;39:44-84.

26. Khorshid F, Ali SS, Alsofyani T, Albar H. Plectranthus tenuiflorus (Shara) Promotes Wound Healing: In vitro and in vivo Studies. Int $\mathbf{J}$ Bot 2010;6:69-80.
27. Sheeba M, Emmanuel S, Revathi K, Ignacimuthu S. Wound healing activity of Cassia occidentalis L. in albino Wistar rats. Int J Integr Biol 2009;8:1-6.

28. Hagh-Nazari L, Goodarzi N, Zangeneh MM, et al. Stereological study of kidney in streptozotocininduced diabetic mice treated with ethanolic extract of Stevia rebaudiana (bitter fraction). Comp Clin Path 2017;26:455-63.

29. Pastar I, Stojadinovic O, Yin NC, et al. Epithelialization in Wound Healing: A Comprehensive Review. Adv Wound Care 2014;3:445-64.

30. Kolaczkowska E, Kubes P. Neutrophil recruitment and function in health and inflammation. Nat Rev Immunol 2013;13:159.

31. Boniakowski AE, Kimball AS, Jacobs BN, et al. Macrophage-Mediated Inflammation in Normal and Diabetic Wound Healing. J Immunol 2017;199:17-24.

32. desJardins-Park HE, Foster DS, Longaker MT. Fibroblasts and wound healing: an update. Regen Med 2018;13:491-5.

Submitted: November 10, 2019

Revision received: December 20, 2019 Accepted for publication: December 22, 2019 